\title{
Socioeconomic environment effect on inferential reasoning of Latin American students
}

\author{
Carmen Flores-Mendoza, ${ }^{1}$ Renan Benigno Saraiva, ${ }^{2}$ Gislene Clemente Vilela Câmara, ${ }^{3}$ Wilma M. Guimarães \\ Lopes, ${ }^{3,4}$ Ana P. Carvalho Pereira Passos, ${ }^{3}$ Ana Maria Valladão Pires Gama, ${ }^{3}$ Viviane de Oliveira Baumgartl, ${ }^{3}$ Laris- \\ sa Assunção Rodrigues, ${ }^{1}$ Ruben Ardila, ${ }^{5}$ Ricardo Rosas, ${ }^{6}$ Miguel Gallegos, ${ }^{7,8}$ Norma Reategui ${ }^{9}$
}

1 Departamento de Psicologia,
Universidade Federal de Minas
Gerais, Minas Gerais, Brazil.
${ }^{2}$ Psychology Department, Universi-
ty of Portsmouth, Hampshire, UK.
${ }^{3}$ Departamento de Psicologia,
Pontificia Universidade Católica
de Minas, Minas Gerais, Brazil.
${ }^{4}$ Departamento de Psicologia,
Universidade FUMEC, Minas
Gerais, Brazil.
${ }^{5}$ Departamento de Psicología,
Universidad Nacional de Colom-
bia, Bogotá, Colombia.
${ }^{6}$ Departamento de Psicología,
Pontificia Universidad Católica
de Chile, Santiago, Chile.
${ }^{7}$ Departamento de Psicología,
Universidad Católica del Maule,
Talca, Chile.
${ }^{8}$ Consejo Nacional de Investiga-
ciones Científicas y Técnicas,
Buenos Aires, Argentina.
${ }^{9}$ Departamento de Psicología,
Universidad San Ignacio de
Loyola, Lima, Perú.

Correspondence:

Carmen Flores-Mendoza

Departamento de Psicologia,

Faculdade de Filosofia e Ciencias

Humanas, Universidad Federal de Minas Gerais.

Av. Antonio Carlos 6627, Belo Horizonte, Minas Gerais, Brazil.

Phone: 31270-901

Email: carmencita@ufmg.br

Received first version: September 13,2016

Second version: February 22, 2017

Accepted: June 14, 2017

doi.10.17711/SM.0185-3325.2017.024

\begin{abstract}
Introduction. Inferential reasoning (IR) is a major component of intelligence, which comprises many different cognitive processes such as perception, memory, and logic. Many studies have proposed that socioeconomic status (SES) has a negligible association with IR, but more recent findings suggest that they may have a higher association when evaluating group instead of individual SES. Objective. The aim of this study is to test the effects of both individual (students) and group (schools) socioeconomic status on IR, comparing different countries of Latin America. Method. The sample was composed of 2358 students aged 14 and 15 years from 52 different schools (44\% public) of five Latin American countries (Argentina, Brazil, Chile, Colombia, and Peru). Participants took part in an inferential reasoning test and answered a socioeconomic questionnaire. Results. SES student showed a small positive correlation with IR $(r=.10, p<.001)$, while SES school had a more pronounced effect on $\operatorname{IR}\left(F[2,1944]=74.68, p<.001, \eta_{p}{ }^{2}=.07\right)$, with higher IR at schools with higher SES. A significant difference of IR between countries $\left(F[4,1976]=20.68, p<.001, \eta_{p}^{2}=.04\right)$, was also found with Peru showing the highest mean. Peru was the country with the higher percentage of private schools in the present study. A multilevel model was fitted using individual and group SES as predictors. Discussion and conclusion. Our findings showed that group SES have a higher predictive value of IR when compared to individual SES. This result suggests that individuals with low SES can benefit from studying on higher SES schools. Future research and the importance of public policies are discussed.
\end{abstract}

Keywords: Inferential reasoning, intelligence, socioeconomic factors, Latin American, schoolchildren.

\section{RESUMEN}

Introducción. El razonamiento inferencial (IR) es un componente importante de la inteligencia que comprende diversos procesos cognitivos, como la percepción, la memoria y la lógica. Muchos estudios han propuesto que el nivel socioeconómico (NSE) tiene una baja asociación con IR, pero hallazgos más recientes sugieren que el NSE del grupo puede tener mayor asociación que el NSE individual con el IR. Objetivo. El objetivo de este estudio es investigar los efectos del nivel socioeconómico individual (estudiantes) y de grupo (escuelas) sobre el IR, haciéndose comparaciones entre diferentes países de América Latina. Método. La muestra estuvo compuesta por 2358 estudiantes con edades comprendidas entre los 14 y los 15 años, de 52 escuelas diferentes (44\% públicas), de cinco países de América Latina (Argentina, Brasil, Chile, Colombia y Perú). Los participantes fueron evaluados con una prueba de razonamiento inferencial y un cuestionario socioeconómico. Resultados. EI NSE individual mostró una pequeña correlación positiva con IR $(r=.10 p<.001)$, mientras que el NSE de grupo tuvo un efecto más pronunciado sobre $\operatorname{IR}\left(F[2,1944]=74.68, p<.001, \eta_{p}{ }^{2}=.07\right)$ con mayor IR en las escuelas con mayor NSE. También se encontró una diferencia significativa de IR entre los países $\left(F[4,1976]=20.68, p<.001, \eta_{p}^{2}=.04\right)$, con un promedio más alto para Perú, el país con mayor número de escuelas particulares en el presente estudio. Se ajustó un modelo multinivel utilizando las variables principales. Discusión y conclusión. Nuestros resultados demostraron que el NSE de grupo tiene un mayor valor predictivo de IR en comparación con el SES individual. Este resultado sugiere que los individuos con un nivel socioeconómico bajo pueden beneficiarse de estudiar en escuelas con SES superiores. Se discuten las futuras investigaciones y la importancia de las políticas públicas.

Palabras clave: Raciocinio inferencial, inteligencia, factores socioeconómicos, América Latina, escolares. 


\section{INTRODUCTION}

Since 2008, the British government has sponsored the Foresight Project on Mental Capital and Wellbeing in order to identify the characteristics of human capital needed to deal with highly competitive economies in the world (Beddington et al., 2008). According to the committee of this project, involving around 450 specialists from several knowledge fields, mental capital refers to people's cognitive abilities and flexible learning, while wellbeing refers to the ability of individuals in engaging productively and positively in their community and finding strategies to develop their potential. Both human capital and wellbeing are individual psychological factors related and developed during the childhood and adolescence. They serve as the cornerstones of quality of life in adulthood. The goal of the British project is to identify the new skills developed in lifelong due to new technology and work in the information age (UK Government Office for Science, 2016). In order to achieve this goal, the current skills in the UK population will be mapped and compared to those that are needed over the next 10 or 20 years.

One of the most important human cognitive processes is reasoning, which is at the core of intelligence (Jensen, 1998). Specifically, inferential reasoning is the cognitive process whereby a person uses perception, thoughts, and assertions to evaluate an information or to infer relationships between elements and establish a conclusion (Sisto, 2006). Inferential reasoning performance, measured in almost all intelligence tests, has explained some of the variability of school achievement performance, job performance, and knowledge of daily events (Beier \& Ackerman, 2001; Gottfredson, 2002; 2006; Gottfredson \& Deary, 2004; Kuncel, Hezlett \& Ones, 2004; Neisser et al., 1996). The same tendency has been found in mental health (Gottfredson \& Deary, 2004). For instance, participants of a Scottish psychological assessment conducted in 1931 were cognitively re-assessed at age 77 . The results indicated that each decrease of IQ standard deviation resulted in a $12 \%$ increase in the likelihood of psychiatric contact (Walker, McConville, Hunter, Deary \& Whalley, 2002). Regarding general health problems, data on 7476 participants in the US National Longitudinal Survey of Youth 1979 indicated that individuals with a higher cognitive score were less likely to suffer chronic lung diseases, heart problems, hypertension, diabetes, arthritis/rheumatism, and emotional or psychiatric problems (Der, Batty \& Deary, 2009). These results are in accordance with a longitudinal study conducted by Ciarrochi, Heaven, and Skinner (2012) with 420 adolescents. Ciarrochi et al. (2012) showed that cognitive abilities related to verbal and math domains, independently of socio-economic status and gender, were associated with good health habits, such as delay in onset of cigarette smoking, less TV watching, more physical exercise, and lower consumption of stimulant drinks.
Thus, results of cross-sectional, longitudinal, and epidemiological cognitive studies are relevant for public policies. Tracking cognitive skills, such as inferential reasoning, and factors of influence, such as socioeconomic status (SES), is a scientific challenge and a public health need. Unfortunately, there are no broad cognitive studies in Latin American. Only specific (e.g., effect of age on cognition or normative data for neuropsychological tests; Ashby-Mitchell, Jagger, Fouweather \& Anstey, 2015; Guàrdia-Olmos, Peró-Cebollero, Rivera \& Arango-Lasprilla, 2015) and local studies (e.g., restricted to a single city or country; Flynn \& Casé, 2012) can be found. One major exception is the SLATINT project.

\section{The SLATINT project}

At the end of 2007, a team of Latin American researchers designed and started a project called "Study of the Latin American Intelligence" (SLATINT), whose goal was to map cognitive abilities of students from Argentina, Brazil, Chile, Colombia, Mexico, and Peru. One of the most important results found in this project was related to the impact of socioeconomic status of schools (SES school) on the intelligence of students (Flores-Mendoza et al., 2015). These results challenged several studies that claimed that social factors have little or null influence on cognitive performance (Colom \& Flores-Mendoza, 2007; Strenze, 2007). Specifically, the study of Flores-Mendoza et al. showed that SES of schools, instead of SES of students, was an important environmental variable for explaining cognitive individual differences. The hypothesis that school composition effects could surpass the impact of individual SES is not new or original. In fact, the effect of schools on the performance of students has frequently been studied since the famous Coleman report was published (Coleman, 1966). Moreover, a recent study conducted by Liu, van Damme, Gielen, and van Den Noortgate (2014) employing multilevel mediation modeling has indicated that students from the same family SES, but enrolled in schools of different SES, had different school performance. Specifically, students enrolled in low SES schools had a lower school performance than students enrolled in high SES schools. A similar phenomenon could be observed in the field of cognitive performance. The effect of SES of school can be stronger than SES of student on cognitive individual differences. For the present paper, this hypothesis was tested with an inductive reasoning test named IR test, which was administered to a sub-sample of the SLATINT project.

\section{METHOD}

\section{Participants}

The study sample was part of the SLATINT project, which was initially composed by a sample of 4074 students. Only 


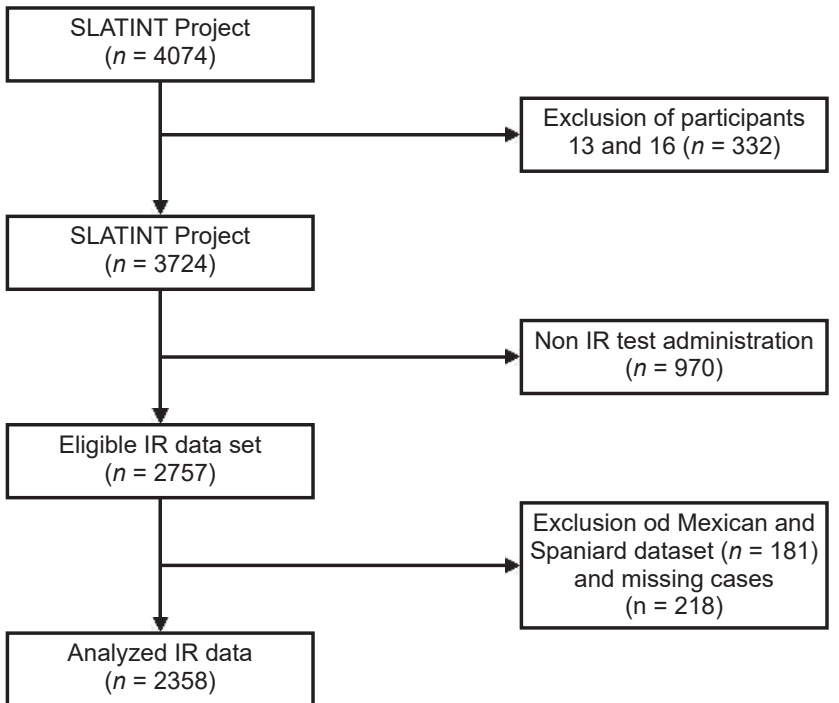

Figure 1. Flowchart of the data cleaning approach.

data from Latin American students aged 14 and 15 years were analyzed. Data from Mexico was not considered due to their reduced size $(N=66)$ and quality (data of the inductive reasoning test came from just one private school). After deletion of missing cases, the final sample was composed of 2358 students aged 14 and 15 years, enrolled in 52 schools (44\% public) of five Latin American cities (Rosario, Argentina; Belo Horizonte, Brazil; Santiago, Chile; Bogota, Colombia, and Lima, Peru). The systematic approach used to obtain the final sample is showed in Figure 1.

The minimum number of students per country was 169 (Chile) and maximum of 639 students (Brazil). Table 1 presents descriptive statistics for individual variables such as sex, age, individual socioeconomic status (SES Student) and school variables, which included type of school (public vs private) and socioeconomic status of schools (SES School). Table 1 indicates a higher percentage of female students, which is in accordance to a survey conducted by the United Nations International Children's Emergency Fund (2016). This survey has verified higher high school enrollment for females when compared to males in most Latin American countries.

In our study, Chilean students represented the youngest sample, and students from Peru and Argentina were the oldest samples. Regarding type of schools, there were more students in public (78\%) than private schools in the Brazilian sample, and Peru had conversely more students in private schools $(86 \%)$. This distribution is partially in accordance with a survey conducted by the Comisión Económica para América Latina y el Caribe (Arcidiácono et al., 2014), which found that Brazil has a higher percentage of public schools and Peru a higher percentage of private schools. However, in the case of Peru 59\% of students were enrolled in low and middle SES schools and had a lower mean in their individual SES $(M=13.64)$. This reveals a characteristic of the Peruvian educational system: there are also private schools in poor areas. According to a Peruvian census conducted by the Ministerio de Educación de Perú (2016), Lima city has $66.7 \%$ of its schools characterized as private, and these schools enroll $49 \%$ of the total student population. Thus, despite of individual SES of students, more private than public schools in the Peruvian sample were expected. However, in general, it is not possible to assert that the Latin American samples analyzed in the present investigation

Table 1

Descriptive statistics of participant and school characteristics by country

\begin{tabular}{|c|c|c|c|c|c|c|c|c|c|c|c|c|}
\hline \multirow[b]{2}{*}{ Participant characteristics } & \multicolumn{2}{|c|}{ Total Sample } & \multicolumn{2}{|c|}{ Argentina } & \multicolumn{2}{|c|}{ Brazil } & \multicolumn{2}{|c|}{ Chile } & \multicolumn{2}{|c|}{ Colombia } & \multicolumn{2}{|c|}{ Peru } \\
\hline & \multicolumn{2}{|c|}{$(n=2358)$} & \multicolumn{2}{|c|}{$(n=429)$} & \multicolumn{2}{|c|}{$(n=639)$} & \multicolumn{2}{|c|}{$(n=169)$} & \multicolumn{2}{|c|}{$(n=640)$} & \multicolumn{2}{|c|}{$(n=481)$} \\
\hline Sex & $\%$ & & $\%$ & & $\%$ & & $\%$ & & $\%$ & & $\%$ & \\
\hline female & 52 & & 51 & & 53 & & 50 & & 54 & & 49 & \\
\hline male & 48 & & 49 & & 47 & & 50 & & 46 & & 51 & \\
\hline Age & $\%$ & & $\%$ & & $\%$ & & $\%$ & & $\%$ & & $\%$ & \\
\hline 14 & 59 & & 53 & & 61 & & 83 & & 62 & & 52 & \\
\hline \multirow[t]{2}{*}{15} & 41 & & 47 & & 39 & & 17 & & 38 & & 48 & \\
\hline & $\mathrm{M}$ & SD & $\mathrm{M}$ & SD & M & SD & M & SD & $\mathrm{M}$ & SD & M & SD \\
\hline SES Student & 14.92 & 2.46 & 13.39 & 1.94 & 15.58 & 2.47 & 16.58 & 1.92 & 15.75 & 2.38 & 13.64 & 1.78 \\
\hline RIN Score & 12.06 & 3.19 & 12.41 & 2.89 & 11.20 & 3.32 & 12.06 & 2.92 & 12.01 & 3.04 & 13.04 & 3.24 \\
\hline School characteristics & \multicolumn{2}{|l|}{$n=52$} & \multicolumn{2}{|l|}{$n=12$} & \multicolumn{2}{|l|}{$n=13$} & \multicolumn{2}{|l|}{$n=5$} & \multicolumn{2}{|l|}{$n=12$} & \multicolumn{2}{|l|}{$n=10$} \\
\hline School type & \multicolumn{2}{|l|}{$\%$} & \multicolumn{2}{|l|}{$\%$} & \multicolumn{2}{|l|}{$\%$} & \multicolumn{2}{|l|}{$\%$} & \multicolumn{2}{|l|}{$\%$} & \multicolumn{2}{|l|}{$\%$} \\
\hline public & \multicolumn{2}{|l|}{44} & \multicolumn{2}{|l|}{50} & \multicolumn{2}{|l|}{78} & \multicolumn{2}{|l|}{38} & \multicolumn{2}{|l|}{30} & \multicolumn{2}{|l|}{13} \\
\hline private & \multicolumn{2}{|l|}{56} & 50 & & 22 & & 61 & & 70 & & 86 & \\
\hline SES School & $\%$ & & $\%$ & & $\%$ & & $\%$ & & $\%$ & & $\%$ & \\
\hline low & 26 & & 21 & & 21 & & 31 & & 30 & & 29 & \\
\hline middle & 39 & & 37 & & 36 & & 33 & & 51 & & 30 & \\
\hline high & 35 & & 42 & & 42 & & 35 & & 18 & & 40 & \\
\hline
\end{tabular}

Note: School type and SES School refers to the percentage of students in the sample that attended the respective type of school. 
were representative of their countries. Therefore, caution is required when interpreting these data.

\section{Instruments and materials}

Inferential Reasoning (IR). It is a test composed by 40 items (Sisto, 2006). Each item presents a set of geometric figures with one figure missing. Four alternative responses are offered for sections $\mathrm{A}$ and $\mathrm{B}$, and six alternatives for sections $\mathrm{C}$ and D. All items have infit and outfit values between .70 and 1.30, which, according to the Rasch measurement model, means that the total of items have a good fit. For the present study, a short version of the IR test was administered using only even items, therefore the IR values range from 0 to 20 . The test took around 15 minutes to complete.

The estimation of SES student was based on two sources: available resources within participants home (e.g., cable TV, MP3 player, phone, computer, internet, videogames, weekend magazine), and parents' level of education. These two sources are the same used by the Criterio Brasil for stratification of social classes according to purchasing power. In our study, each item of available resources in home represented one point. The lowest level of schooling of parents (estimated as average from mother and father) was equivalent to one point, and the highest one (university) accounted for 4 points. The sum of points was the socioeconomic index of the student, which could range from 0 to 20. SES schools was an ordinal variable related to a classification (low, middle, and high) made by the responsible for data collection in each country. Samples of schools from Peru and Brazil were randomly selected. In the case of Peru, the researcher collaborated with technicians of the Ministerio de Educación (Ministry of Education). In the case of Brazil, the researcher had access to the dataset produced by Soares and Andrade (2006) regarding the distribution of socioeconomic levels of schools located in the Belo Horizonte city, which permitted the random selection of Brazilian schools for the present study. Samples from Chile, Argentina, and Colombia were non-probabilistic; i.e., researchers of these countries selected schools based on their knowledge of the infrastructure of each school and the socioeconomic characteristics of the neighborhood where it was located. At least two schools representative from each socioeconomic stratum (low, middle, and high SES) were required. In order to render validity to the socioeconomic classification of the selected schools of Chile, Argentina, and Colombia, researchers were asked to complete a questionnaire with items concerning sanitary and urban conditions of the neighborhoods (e.g., waste collection system, drainage system, public street lighting, presence of paved streets) where each school was located. Items regarding school environment (e.g., school instruction time, class size, mathematic instruction time, presence of computers) also composed the questionnaire. The points accumulated by each item were summed and produced a total score. This questionnaire was filled one year after finishing the data collection. Unfortunately, the Argentinian researcher could not collect information to report. The correlation between the total score of the questionnaire and the SES school classification was .72 $(p=.05)$ for Chilean schools and $.63(p=.03)$ for Colombian schools, which indicated good validity of the classifications made by the researchers. In the case of Argentina, the correlation obtained of .74 between SES individual and SES school was considered as evidence of good validity.

\section{Procedure}

The Ethical Committee of the Universidade Federal de Minas Gerais-Brazil approved the SLATINT project (N. 263/07). The SLATINT study was conducted during the period 2007 to 2011 ( $80 \%$ of the data were collected during 2008 and 2009), and it was designed to administrate two cognitive measures to the total sample in one session. Other measures, such as the IR test, were administered to a sub-sample of each country in a second session. The reason for testing a sub-sample was related to logistic constraints of the participant schools. The IR test was conducted in classrooms by psychology students trained by the responsible of data collection in each country.

\section{Statistical analyses}

A multilevel linear model was used to test the effects of individual and group SES on IR performance. Multilevel analysis is necessary when data are nested (as in the current study), because within-groups observations are correlated, and the underlying structure of the factors may vary from one level of analysis to the next (Raudenbush \& Bryk, 2002). In our study, this modelling approach allowed for the examination of the effects of interest at individual levels, and between other levels of spatial aggregation (e.g., schools and countries). Analyses were conducted using R statistical software packages (R Development Core Team, 2016). The package lme4 was used to fit multilevel models (Douglas, Martin, Ben \& Steve, 2015).

A bottom-up model building strategy was used, which started with the simplest possible model and proceeded by adding and testing new parameters (Hox, Moerbeek \& van de Schoot, 2010). Students SES was centered around the grand mean and categorical variables were dummy coded. Initially an intercept-only model was used as baseline, followed by a model including the lower level (SES Student) and high level (SES School and School Type) explanatory variables.

In the next step intercepts were allowed to vary between different schools and between the five countries. Finally, a model allowing for random effects between schools and countries was tested, but no significant evidence that random 


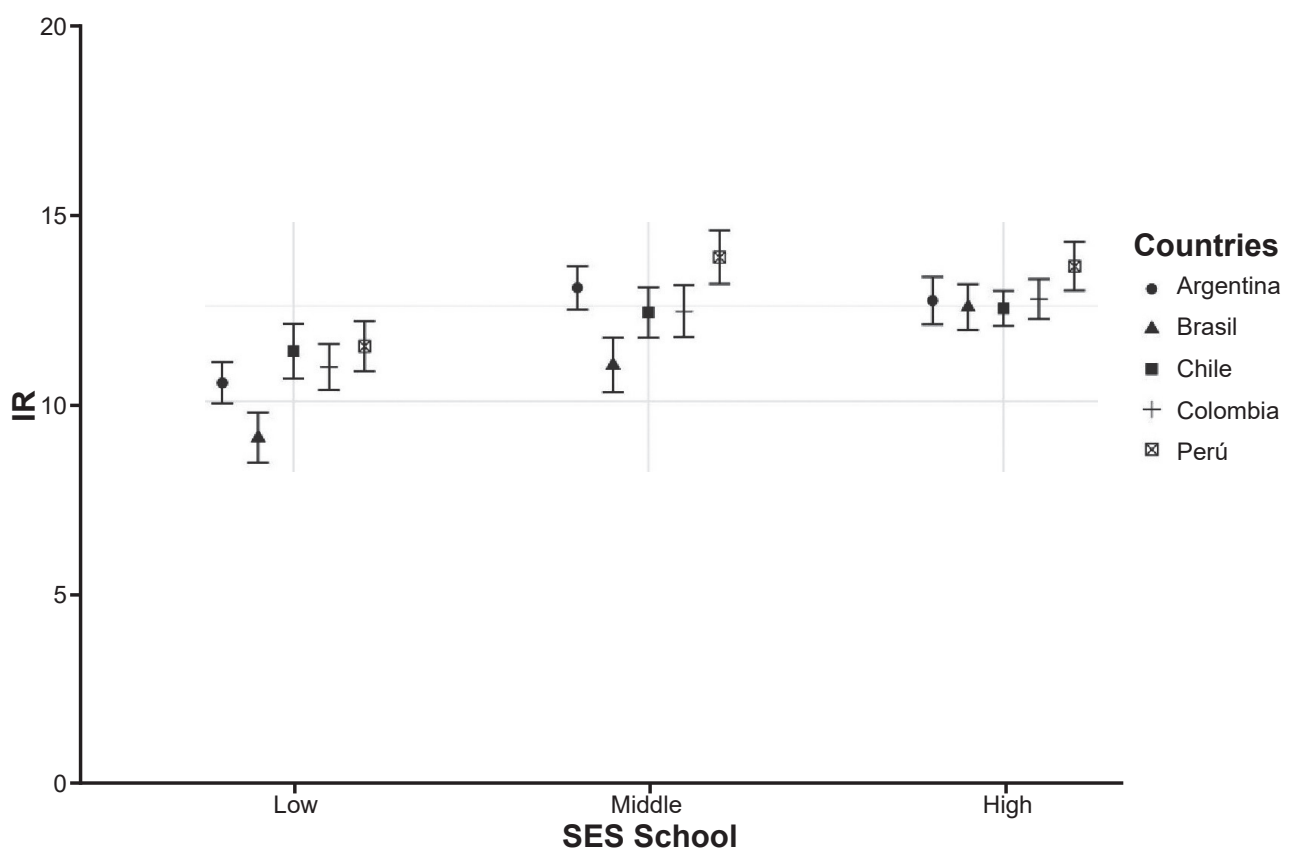

Figure 2. Effect of SES School on IR by country.

slopes improved the model was found. Therefore, the final model is as follows:

$Y_{i}=\beta_{0}+\beta_{1} I$ (SES Student) $+\beta_{2} I($ SES School $)+\beta_{3} I$ (School Type $)+b_{1, j[]}+b_{2, K[]}+\epsilon_{i}$

Where $i$ denotes participant, $j[\mathrm{i}$ ] denotes group level for school and $k$ [i] denotes group level for country, $\beta$ indicates a fixed-effect coefficient and $b$ indicates a random variable.

$$
\begin{aligned}
& \mathrm{b}_{1}=N\left(0, \sigma_{2}^{1}\right. \\
& \mathrm{b}_{2}=N\left(0, \sigma_{2}^{2}\right. \\
& \epsilon=N\left(0, \sigma_{\mathrm{r}}^{2}\right.
\end{aligned}
$$

\section{RESULTS}

Analysis of variance revealed a significant difference of IR between countries $\left(F[4,1976]=20.68, p<.001, \eta_{\mathrm{p}}{ }^{2}=.04\right)$, with Peru showing the highest mean, followed by Argentina and Chile (Table 1). There was also a significant effect of school types on IR $(t[1734]=12.63, p<.001, d=.58)$, with private schools showing highest IR scores $(M=12.85$, $S D=2.93)$ when compared to public schools $(M=11.05$, $S D=2.93)$.

Similarly, SES School had a significant effect on IR ( $F$ $\left.[2,1944]=74.68, p<.001, \eta_{\mathrm{p}}{ }^{2}=.07\right)$, with higher IR at schools with higher SES, when compared to medium and low SES schools. Analysis of contrasts revealed a more pronounced difference from low to medium when comparing to the difference from medium to high (Figure 2). There was a significant but negligible effect of sex on IR favoring females $(t[1910]=2.86, p<.001, d=.12)$.

Table 2 presents the final model coefficients for the effects of SES Student, SES School, and Type of School on IR.

\begin{tabular}{|c|c|c|c|c|c|c|}
\hline & \multicolumn{3}{|c|}{ Null Model } & \multicolumn{3}{|c|}{ Final Model } \\
\hline & Estimate & SE & $t$ & Estimate & SE & $t$ \\
\hline Intercept & 12.09 & .07 & 164.75 & 10.53 & .38 & 27.50 \\
\hline SES student & & & & .04 & .03 & 1.13 \\
\hline \multicolumn{7}{|c|}{ SES school $($ Low $=0)$} \\
\hline Middle & & & & 1.60 & .42 & 3.75 \\
\hline High & & & & 1.74 & .47 & 3.66 \\
\hline \multicolumn{7}{|c|}{ School type $($ Public $=0)$} \\
\hline Private & & & & .64 & .40 & 1.59 \\
\hline -2 log-likelihood & -4815.90 & & & -4662.53 & & \\
\hline AIC & 9635.81 & & & 9340.92 & & \\
\hline $\mathrm{BIC}$ & 9646.88 & & & 9385.22 & & \\
\hline
\end{tabular}

Table 2

Multilevel estimates for models predicting IR 


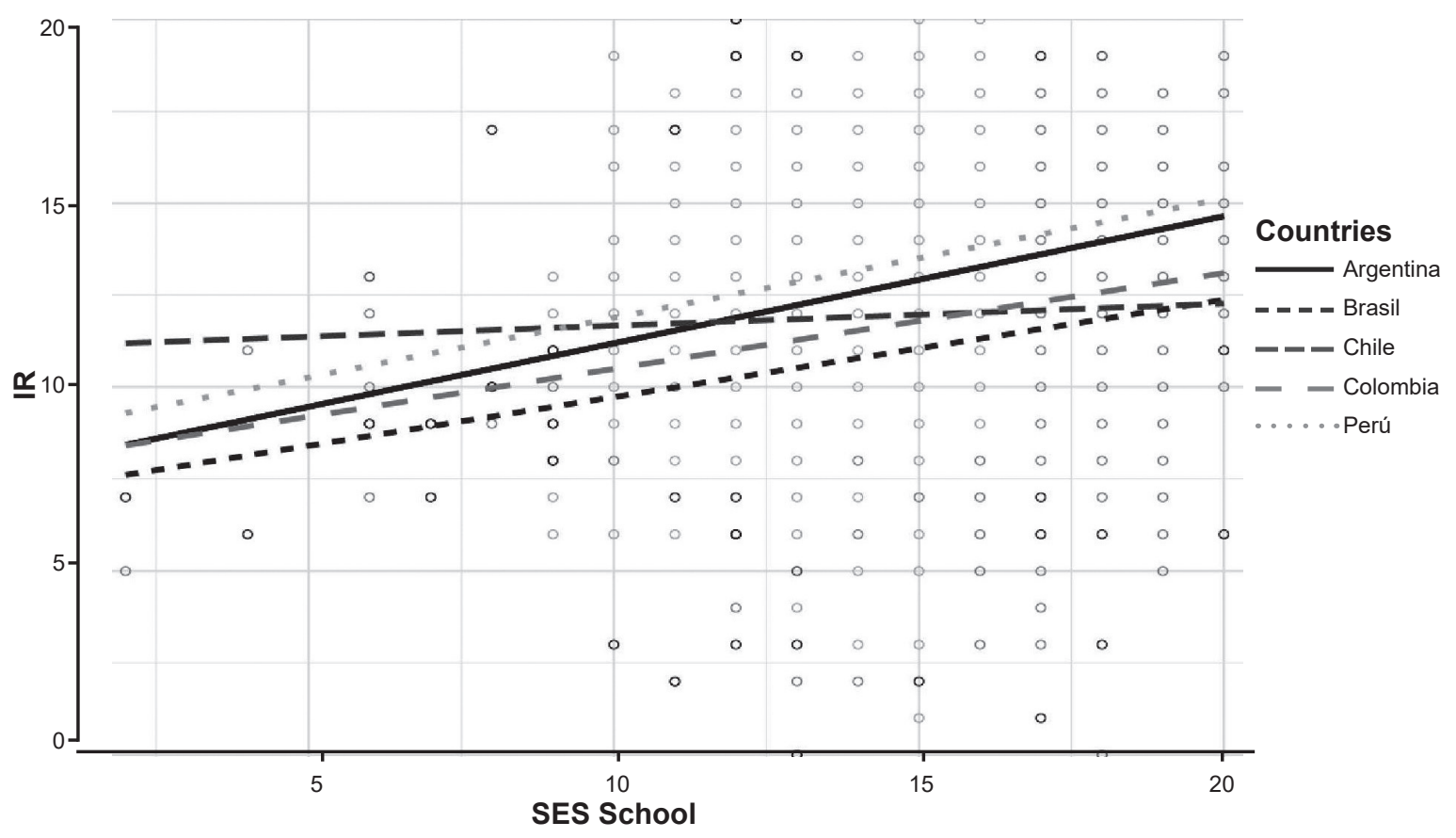

Figure 3. Effect of SES Student on IR by country.

Both SES Student and SES School had a positive association with IR, with SES School yielding a highest contribution to the model. Indeed, analysis of covariance between SES Student and IR revealed a small correlation $(r=.10, p<.001)$. Chile showed the smallest correlation when testing this same analysis for each country $(r=.04, p=.63)$, and other countries correlations ranged from .17 to .22 (all $p<.001$; Figure $3)$. Despite these differences, adding a random slope coefficient to the multilevel model based on country did not improve the model. However, there is a significant variation of intercepts between different schools and different countries. Possible interactions between the effects of SES student and SES school on IR were tested, but no significant evidence of difference was found.

\section{DISCUSSION AND CONCLUSION}

As described at the beginning of this paper, the new challenges for public policies in the world are to gather information about the cognitive skills of the population and to identify at what level they are and factors that affect them. In this direction, the present study, which is part of the SLATINT project, shows results about inferential reasoning in samples of students from five Latin American countries.

Inferential statistics indicated significant mean differences between private and public schools, which is an unsurprisingly result for the educational system of Latin American. In addition, there were significant IR mean differences among countries, with the highest mean for the Pe- ruvian sample and the lowest mean for the Brazilian one. However, this result should be analyzed with caution, given that the Peruvian sample had the highest proportion of private school students (86\%) while the Brazilian sample had the smallest (22\%). A surprising result was that females and males did not have different performances on IR. Usually, the literature regarding reasoning tasks has presented significant mean differences favoring males (Voyer, Voyer \& Bryden, 1995). However, new studies have pointed out a reduction of these cognitive sex differences in the last years (Miller \& Halpern, 2014). Considering that the Brazilian normative study for the IR test has also presented a slight female superiority, it is necessary to continue to track this tendency in the next decades (Sisto, 2006).

The multilevel analysis, which does not assume independence among variables, indicated the most important result: SES school was the best predictor of IR performance instead of SES student. This result was found in both the total sample and in each sub-sample. Furthermore, the cognitive performance of low SES school students was very far from students from other schools. The cognitive difference between students from middle and high SES schools was less pronounced. In this regard, it could be said that low SES schools cover students from low SES families, and high SES schools cover students from high SES families, and, for this reason, aggregated scores (SES schools) could inflate the correlation coefficients between SES schools and intelligence. However, the correlation between SES student and SES school in our study was not high $(r=.42, p<.001)$. This moderate association means that there was certain indepen- 
dence in our samples between the social economic status of schools and the socioeconomic status of their students.

Our results corroborate those obtained by Flores-Mendoza et al (2015) and studies such as the one by Duarte, Bos, and Moreno (2010) regarding Latin American school performance. In that study, only $1.7 \%$ of the school achievement variance was explained by variability in socioeconomic status of students within the school (individual SES), while $49.2 \%$ of the variance was explained by socioeconomic characteristics of schools (or SES-school). Specifically, Duarte, Bos, and Moreno found that students from Brazil, Uruguay, Colombia, and Peru had a higher percentage of the changes in their score influenced by between-school variation $(78.9 \% ; 76.6 \% ; 70.6 \%$, and $60.0 \%$, respectively).

Why SES school, and not SES student, was a better predictor of cognitive differences? SES student means available resources within their home, and SES school means available conditions out of home. In our study, SES school covered not only school conditions; also, it covered neighborhood conditions where the school was located. In this sense, our study showed that students, independently of their family social economic status, may benefit from high quality of school environment for their cognitive development.

In this regard, Jargowsky and El Komi (2011) conducted a study concerning the effect of school context and neighborhood on student performance in Texas, USA. Using different criteria for measuring the school environment (e.g., percent of students eligible for free and reduced price lunch; turnover; average math and reading scores; percent of children in married couple families; percent of adults who were college graduates), the authors identified a strong effect of school context, and a little, but significant, effect of neighborhood on student performance. Obviously, it is not possible to compare the narrow variability of school environment in USA with the broad variability of school environment present in Latin America. However, the message is the same: the environment can overcome the limitations within family and positively influence the cognitive development of students.

Inferential reasoning is a psychological resource related to logical thinking, which allows individuals to choose the best options; allows dealing with new marketplaces challenges, and achieving longtime health. In this sense, some governments, especially from developed countries, have begun to track the cognitive conditions of their populations. Studies based on the social conditions of the students have shown a small effect of environment on cognitive performance. However, our study presented that environment, based on school's context, has a moderate effect on the cognitive performance of students. This is good news for governmental policies, but at the same time, it is a great challenge to improve school's environment, especially in developing countries.
This cross-sectional study is a preliminary investigation regarding cognitive skills (specifically inferential reasoning) of Latin American students. We recognize that the samples used were non-representative of their countries and future studies could overcome this limitation. However, in this era of increasing technological complexity and serious consequences for our populations, we consider that, despite family background differences, the results obtained regarding the strong effect of components of school on inferential reasoning deserve some attention from governmental institutions.

\section{Funding}

This paper received financial support from CNPq (N. 472181/20130), FAPEMIG (PPM 03/2014) and VETOR publishing.

\section{Conflict of interests}

The authors declare they have no conflict of interests.

\section{REFERENCES}

Arcidiácono, M., Cruces, G., Gasparini, L., Jaume, D., Serio, M., \& Vázquez, E. (2014). La segregación escolar público-privada en América Latina. Serie Politicas Sociales , 139, 1-37. Retrieved from: http://repositorio.cepal.org/bitstream/ handle/11362/36757/S2014249_es.pdf?sequence=1\&isAllowed=y

Ashby-Mitchell, K., Jagger, C., Fouweather, T., \& Anstey, K. J. (2015). Life Expectancy with and without Cognitive Impairment in Seven Latin American and Caribbean Countries. PloS one, 10(3), e0121867. doi:10.1371/journal.pone.0121867

Beddington, J., Cooper, C. L., Field, J., Goswami, U., Huppert, F. A., Jenkins, R., ... Thomas, S. M. (2008). The mental wealth of nations. Nature, 455(7216), 10571060. doi: $10.1038 / 4551057 \mathrm{a}$

Beier, M. E., \& Ackerman, P. L. (2001). Current-events knowledge in adults: An investigation of age, intelligence, and nonability determinants. Psychology and aging, 16(4), 615-628. doi: 10.1037/0882-7974.16.4.615

Ciarrochi, J., Heaven, P. C., \& Skinner, T. (2012). Cognitive ability and health-related behaviors during adolescence: A prospective study across five years. Intelligence, 40(4), 317-324. doi: 10.1016/j.intell.2012.03.003

Coleman, J. S. (1966). Equality of educational opportunity (Vol. 2). Washington, DC: US Department of Health, Education, and Welfare, Office of Education.

Colom, R., \& Flores-Mendoza, C. E. (2007). Intelligence Predicts Scholastic Achievement Irrespective of SES Factors: Evidence from Brazil. Intelligence, 35(3), 243-251. doi: 10.1016/j.intell.2006.07.008

Der, G., Batty, G. D., \& Deary, I. J. (2009). The association between IQ in adolescence and a range of health outcomes at 40 in the 1979 US National Longitudinal Study of Youth. Intelligence, 37(6), 573-580. doi: 10.1016/j.intell.2008.12.002

Douglas, B., Martin, M., Ben, B., Steve, W. (2015). Fitting linear mixed-effects models using lme4. Journal of Statistical Software, 67(1), 1-48.

Duarte, J., Bos, M. S., \& Moreno, M. (2010). Inequity in School Achievement in Latin America: Multilevel Analysis of SERCE results according to the socioeconomic status of students. Inter-American Development Bank. IDB WORKING PAPER SERIES No. IDB-WP-180. Retrieved from: https://publications.iadb.org/ bitstream/handle/11319/2558/Inequity\%20in\%20School\%20Achievement $\% 20$ in\%20Latin\%20America.pdf?sequence=1\&isAllowed=y

Flores-Mendoza, C., Mansur-Alves, M., Ardila, R., Rosas, R. D., Guerrero-Leiva, M. K., Maqueo, Lucio-Gómez, M. E., ... Burga, A. B. (2015). Fluid intelligence and school performance and its relationship with social variables in Latin American samples. Intelligence, 49, 66-83. doi: 10.1016/j.intell.2014.12.005

Flynn, J. R., \& Rossi-Casé, L. (2012). IQ gains in Argentina between 1964 and 1998. Intelligence, 40(2), 145-150. doi: 10.1016/j.intell.2012.01.006

Gottfredson, L. S. (2002). Where and Why g Matters: Not a Mystery. Human Performance, 15(1-2), 25-46. doi: 10.1080/08959285.2002.9668082 
Gottfredson, L. S., \& Deary, I. J. (2004). Intelligence Predicts Health and Longevity, but Why? Current Directions in Psychological Science, 13(1), 1-4. doi: 10.1111/j.0963-7214.2004.01301001.x

Gottfredson, L. S. (2006). Consequências sociais das diferenças de grupo na capacidade cognitiva. In C. Flores-Mendoza \& R. Colom (Eds.), Introdução à Psicologia das Diferenças Individuais (433-456). Porto Alegre: Artmed.

Guàrdia-Olmos, J., Peró-Cebollero, M., Rivera, D., \& Arango-Lasprilla, J. C. (2015). Methodology for the development of normative data for ten Spanish-language neuropsychological tests in eleven Latin American countries. NeuroRehabilitation, 37(4), 493-499. doi: 10.3233/NRE-151277

Hox, J. J., Moerbeek, M., \& van de Schoot, R. (2010). Multilevel analysis: Techniques and applications. New York: Routledge.

Jargowsky, P. A., \& El Komi, M. (2011). Before or After the Bell? School Context and Neighborhood Effects on Student Achievement. In: S. Wachter, E. L. Birch, \& H. Newberger (Eds.), Neighborhood and Life Chances: How Place Matters in Modern America (pp. 50-72). Philadelphia: University of Pennsylvania Press.

Jensen, A. R. (1998). The g Factor: The Science of Mental Ability. Westport: Praeger.

Kuncel, N. R., Hezlett, S. A., \& Ones, D. S. (2004). Academic Performance, Career Potential, creativity, and Job Performance: Can One Construct Predict Them All? Journal of Personality and Social Psychology, 86(1), 148-161. doi: 10.1037/0022-3514.86.1.148

Liu, H., van Damme, J., Gielen, S., \& van Den Noortgate, W. (2014). School processes mediate school compositional effects: model specification and estimation. British Educational Research Journal, 41(3), 423-447. doi: 10.1002/berj.3147

Miller, D. I., \& Halpern, D. F. (2014). The new science of cognitive sex differences. Trends in cognitive sciences, 18(1), 37-45. doi: 10.1016/j.tics.2013.10.011

Ministerio de Educación de Perú (2016). Magnitudes. ESCALE: Unidad de Estadística Educativa. Retrieved from: http://escale.minedu.gob.pe/magnitudes
Neisser, U., Boodoo, G., Bouchard T. J., Jr., Boykin, A. W., Brody, N., Ceci, S. J., ... Urbina, S. (1996). Intelligence: Knowns and unknowns. American psychologist, 51(2), 77-101. doi: 10.1037/0003-066X.51.2.77

Raudenbush, S. W., \& Bryk, A. S. (2002). Hierarchical linear models: Applications and data analysis methods (Vol. 1). California: Sage Publications Inc.

R Development Core Team. R: A language and environment for statistical computing. R Foundation for Statistical Computing, Vienna. [computer software] Retrieved from http://www.R-project.org. 2016.

Sisto, F. F. (2006). Teste de raciocínio inferencial. São Paulo: Vetor Editora Psicopedagógica.

Soares, J. F., \& Andrade, R. J. (2006). Socioeconomic status, quality and equity in the schools of Belo Horizonte. Ensaio: Avaliação e Políticas Públicas em Educação, 14(50), 107-125. doi: 10.1590/S0104-40362006000100008

Strenze, T. (2007). Intelligence and socioeconomic success: A meta-analytic review of longitudinal research. Intelligence, 35(5), 401-426. doi: 10.1016/j.intell.2006.09.004

Voyer, D., Voyer, S., \& Bryden, M. P. (1995). Magnitude of sex differences in spatial abilities: A meta-analysis and consideration of critical variables. Psychological Bulletin, 117(2), 250-270. doi: 10.1037/0033-2909.117.2.250

UK Government for Science. (2016). Future of skills and lifelong learning [Web log post]. Retrieved from: https://www.gov.uk/government/collections/future-ofskills-and-lifelong-learning.

United Nations International Children's Emergency Fund. (2016). Monitoring the Situation of Children and Women. Retrieved from: http://data.unicef.org/topic/ education/secondary-education/\#

Walker, N. P., McConville, P. M., Hunter, D., Deary, I. J., \& Whalley, L. J. (2002). Childhood mental ability and lifetime psychiatric contact: A 66-year follow-up study of the 1932 Scottish Mental Ability Survey. Intelligence, 30(3), 233-245. doi: 10.1016/S0160-2896(01)00098-8 